\title{
Understanding Hotel Employees' and Guests' Perceptions of Smart Hotels Using Q Methodology
}

\author{
Ye Shen ${ }^{(\text {四 })}$ \\ California Polytechnic State University, San Luis Obispo, CA 93407, USA \\ yeshen@calpoly.edu
}

\begin{abstract}
Nowadays, hotels are adopting high technologies to improve the quality of their facilities and services to build competitive advantages. Although smart hotels are an emerging trend, no known studies have investigated hotel employees' and guests' perceptions of this kind of hotel. This research will investigate how hotel employees and guests perceive the benefits and drawbacks of smart hotels using Q methodology.
\end{abstract}

Keywords: Smart hotel $\cdot$ Q methodology $\cdot$ Perception $\cdot$ Hotel guest $\cdot$ Hotel employee

\section{Introduction}

A smart hotel is "an intelligent hotel with a range of information technologies working together to let the guests have an honorable and convenient vacation environment" [1] (p. 42). Different technology innovations, such as service robots, Artificial Intelligence (AI), and the Internet of Things (IoT), have been implemented by certain hotels to enhance customer experiences. Opened in December 2018, Flyzoo Hotel in China is the world's first full-featured smart hotel that allows customers to enjoy its intelligent experience and facilities. Hilton Hotels have collaborated with IBM and used an AI robot, Connie, to provide guests with concierge service and travel suggestions. Hôtel Monville in Montreal is the first hotel in Canada using autonomous delivery robots for room service. As hotels adopt high technologies to improve the quality of their facilities and services to build competitive advantages, smart hotels are an important trend to watch out for.

Although smart hotels are an emerging trend, no known studies have investigated hotel employees' and guests' perceptions of this kind of hotel. Hotel employees and guests are two important stakeholders for a hotel. The stakeholder theory reveals that business operation needs to balance the benefits of every related group [2]. From a managerial perspective, the stakeholder theory shows that managerial decision-making will be influenced directly by the various groups [3]. Therefore, there is a need to understand how hotel employees and guests evaluate smart hotels, which will impact the development and adoption of technologies in hotels. 
Q methodology is a qualitative research approach to explore attitudes, beliefs, and opinions of different stakeholders. This research method is especially useful for understanding new phenomena [4]. It analyzes shared subjectivity among people based on inter-correlated and factor analysis, resulting in several potential factor solutions. The Q-factor analysis can cluster participants into different groups and have insights into the relationships between the characteristics of the participants and each factor [5]. As "a method for the scientific study of human subjectivity" [6] (p. 12), Q methodology has been widely used to explore different stakeholders' subjectivity, such as visitors' and locals' tourism experiences [7] and Chinese and Canadian perceptions of photographic images of travel destinations [8].

The goal of this research is to understand hotel employees' and hotel guests' attitudes towards smart hotels. The $\mathrm{Q}$ methodology will be used to understand employees' and guests' perceptions. This study will answer the following research questions: (1) What are the benefits and drawbacks of smart hotels from the perspectives of hotel employees and guests? (2) What is the typology of the smart hotel employees and smart hotel guests? (3) What are the characteristics of each group?

\section{Methodology}

To conduct a Q methodology, the first step is to develop Q-sort statements (Fig. 1). This research has reviewed the literature related to people's perceptions of smart hotels, including perspectives from both hotel employees and guests. There are pros and cons associated with smart hotels. Smart hotels can shorten customer waiting times [9], provide seamless experiences [10], enhance service quality [10], and improve service efficiency [11]. However, others have argued that smart hotels lack personal interactions, raise privacy issues, and have potential technological failure [12].

In addition, hotel guests' reviews on the smart hotel, including Flyzoo Hotel, Hôtel Monville, and Hilton McLean in Virginia (Connie), will be analyzed to further develop Q-sort statements. Choosing these three hotels is because they have a good number of guest reviews on TripAdvisor and Booking.com. It will allow researchers to collect adequate data to further understand guests' attitudes towards the smart hotel. Additionally, in-depth interviews will be conducted to understand hotel employees' and residents' perceived benefits and drawbacks of smart hotels. A total of 15 hotel employees working at a smart hotel and 15 hotel guests who have stayed in a smart hotel will be invited to an interview. The transcripts will be analyzed in NVivo to add or revise the Q-sort statements derived from the literature review and content analysis. It is estimated that this research will develop around 30 statements.

The Q-sort statements are the concourse of the attitudes of both hotel employees and guests. For example, hotel employees may be more likely to judge the smart hotels regarding maintenance and work replacement, while hotel guests may focus on the aspects of excitement and fun. The statements in this research will include both different views of employees and guests. It will allow researchers to better understand how employees rate the benefits that smart hotels could bring to the hotel guests. It will also give insights into how hotel guests evaluate how the technology can benefit hotel employees. 
In the data collection, participants (i.e., hotel employees and hotel guests) will be asked to rank the Q-sort statements based on their agreement levels (Fig. 2). And then, a post sorting interview will be conducted to understand why participants ranked the statements in that way and their attitudes towards smart hotels. In addition, the demographic information of the participants will be collected. As a large sample size may negate complexities and slight distinctions, 80 is deemed a valid number. Therefore, this research will recruit 40 hotel guests who have stayed in a smart hotel and 40 hotel employees who worked in a smart hotel.

Data will be analyzed in PQMethod to compare the different factor solutions. The most appropriate factor-solution will be selected based on correlation matrix, the total variance explained, and the number of subjects that loaded on factors [5].

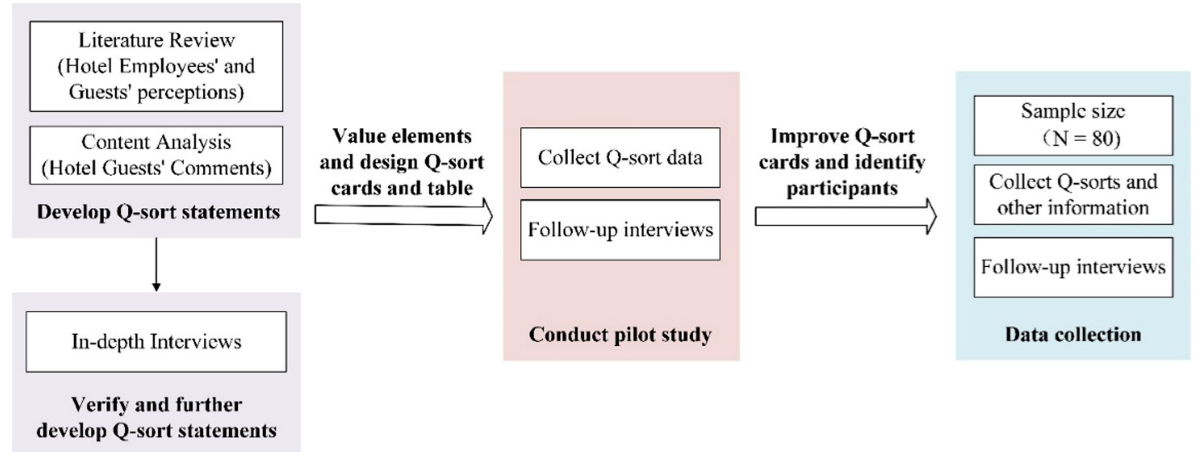

Fig. 1. Data collection process

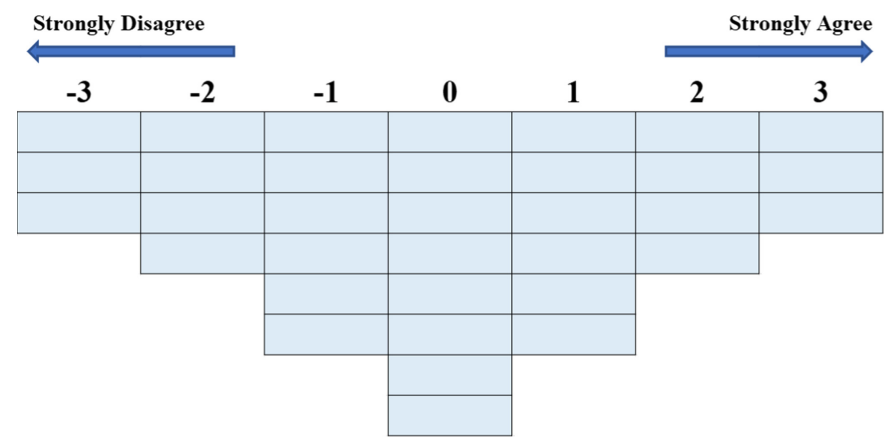

Fig. 2. Fixed distribution used for the Q-sort statements 


\section{Expected Results and Contributions}

First, this research will summarize the benefits and drawbacks of smart hotels from the perspectives of hotel employees and guests. Second, the typology of smart hotel employees and smart hotel guests will be developed. Third, the characteristics of the employees and guests will be analyzed along with the typology.

This research will give insights into the benefits that hotel guests most value. Since building or converting to a smart hotel is costly, both hotel employees' and guests' perceptions will have implications for the development of smart hotels. Additionally, the perceptions will be categorized into several factors based on Q-factor analysis, resulting in a typology of perceptions. Additionally, the characteristics of the participants loaded on the factors will give insights into how to better attract potential smart hotel guests and mitigate hotel employees' potential resistance to smart hotels. The benefits that perceived across different groups will shed light on marketing strategies and human resources practices: These benefits could be advocated in marketing messages for customer acquisition or embedded in training materials to enhance employees' support for smart hotel features (e.g., service robots, AI, and IoT).

\section{References}

1. Wu H-C, Cheng C-C (2018) Relationships between technology attachment, experiential relationship quality, experiential risk and experiential sharing intentions in a smart hotel. J Hosp Tour Manag 37:42-58

2. Freeman RE (1984) Strategic management: a stakeholder approach. Pitman, Boston

3. Jones TM (1995) Instrumental stakeholder theory: a synthesis of ethics and economics. Acad Manag Rev 20(2):404-437

4. Hunter WC (2011) Rukai indigenous tourism: representations, cultural identity and Q method. Tour Manag 32(2):335-348

5. Shen Y, Choi HC, Joppe M, Yi S (2020) What motivates visitors to participate in a gamified trip? A player typology using Q methodology. Tour Manag 78:104074

6. McKeown BF, Thomas DB (1988) Q methodology. Sage, Newbury Park

7. Fairweather JR, Swaffield SR (2001) Visitor experiences of Kaikoura, New Zealand: an interpretive study using photographs of landscapes and Q Method. Tour Manag 22(3):219228

8. Dewar K, Li WM, Davis CH (2007) Photographic images, culture, and perception in tourism advertising: a Q methodology study of Canadian and Chinese university students. J Travel Tour Mark 22(2):35-44

9. Kokkinou A, Cranage DA (2013) Using self-service technology to reduce customer waiting times. Int J Hosp Manag 33:435-445

10. Kuo C-M, Chen L-C, Tseng C-Y (2017) Investigating an innovative service with hospitality robots. Int J Contemp Hosp Manag 29(5):1305-1321 
11. Tuomi A, Tussyadiah IP, Stienmetz J (2021) Applications and implications of service robots in hospitality. Cornell Hosp Q 62(2):232-247

12. Kelly P, Lawlor J, Mulvey M (2013) Customer decision-making processes and motives for self-service technology usage in multichannel hospitality environments. Int J Electron Cust Relatsh Manag 7(2):98-116

Open Access This chapter is licensed under the terms of the Creative Commons Attribution 4.0 International License (http://creativecommons.org/licenses/by/4.0/), which permits use, sharing, adaptation, distribution and reproduction in any medium or format, as long as you give appropriate credit to the original author(s) and the source, provide a link to the Creative Commons license and indicate if changes were made.

The images or other third party material in this chapter are included in the chapter's Creative Commons license, unless indicated otherwise in a credit line to the material. If material is not included in the chapter's Creative Commons license and your intended use is not permitted by statutory regulation or exceeds the permitted use, you will need to obtain permission directly from the copyright holder. 